\title{
Near-infrared spectroscopy as a predictor of clinical deterioration: a case report of two infants with duct-dependent congenital heart disease
}

\author{
Mirthe J. Mebius ${ }^{1 *}$, Gideon J. du Marchie Sarvaas ${ }^{3}$, Diana W. Wolthuis ${ }^{2}$, Beatrijs Bartelds ${ }^{3}$, Martin C. J. Kneyber,
} Arend F. Bos ${ }^{1}$ and Elisabeth M. W. Kooi ${ }^{1}$

\begin{abstract}
Background: Some infants with congenital heart disease are at risk of in-hospital cardiac arrest. To better foresee cardiac arrest in infants with congenital heart disease, it might be useful to continuously assess end-organ perfusion. Near-infrared spectroscopy is a non-invasive method to continuously assess multisite regional tissue oxygen saturation.

Case presentation: We report on two infants with duct-dependent congenital heart disease who demonstrated a gradual change in cerebral and/or renal tissue oxygen saturation before cardiopulmonary resuscitation was required. In both cases, other clinical parameters such as heart rate, arterial oxygen saturation and blood pressure did not indicate that deterioration was imminent.

Conclusions: These two cases demonstrate that near-infrared spectroscopy might contribute to detecting a deteriorating clinical condition and might therefore be helpful in averting cardiopulmonary collapse and need for resuscitation in infants with congenital heart disease.
\end{abstract}

Keywords: Congenital heart disease, Near-infrared spectroscopy, Newborn infants, Cardiac arrest, Cardiopulmonary resuscitation, Intensive care, Case report

\section{Background}

Some infants with congenital heart disease (CHD) are at risk of cardiac arrest during hospitalization [1]. Inhospital cardiac arrest occurs in approximately $2 \%$ to $6 \%$ of children admitted to paediatric intensive care units [2, 3]. Through earlier recognition, cardiac arrest may be prevented and outcomes and survival may be improved [4].

Monitoring end-organ perfusion might help recognizing clinical deterioration at an early stage. Near-infrared spectroscopy (NIRS) is a non-invasive clinical tool to continuously assess multisite regional tissue oxygen saturation $\left(\mathrm{rSO}_{2}\right)$ [5]. It is based on the relative transparency of

\footnotetext{
* Correspondence: m.j.mebius01@umcg.nl

${ }^{1}$ University Medical Center Groningen, Beatrix Children's Hospital, Division of Neonatology, University of Groningen, Hanzeplein 1, 9713 GZ Groningen, The Netherlands

Full list of author information is available at the end of the article
}

biological young tissue (bone, skin, soft tissue) and the ability to differentiate oxygenated hemoglobin from deoxygenated hemoglobin as they have distinct absorption spectra. The ratio between oxygenated and total hemoglobin represents the regional tissue oxygen saturation [6]. In infants with CHD, multiple studies have investigated tissue oxygenation at various moments during early life [7-14]. Most studies addressed the intraoperative and postoperative period [7-10], but cerebral $\mathrm{rSO}_{2}$ was also assessed preoperatively in some studies [11-14]. To our knowledge, however, multisite tissue oxygen saturation as a predictor of clinical deterioration in neonates with $\mathrm{CHD}$ has not been described before.

We discuss two cases in which continuous monitoring of multisite tissue oxygen saturation using NIRS indicated a deteriorating clinical condition which eventually led to cardiac arrest. 


\section{Case presentation}

Both cases in this report were part of a prospective observational cohort study (registration number NTR5233), which was conducted between May 2014 and August 2016. Parental informed consent was obtained in both cases. We measured cerebral and renal $\mathrm{rSO}_{2}$ using INVOS 5100c near-infrared spectrometers (Somanetics Corporation, Troy, Michigan, USA) in combination with neonatal sensors (Somanetics Corporation). Nurses were not instructed to act on certain $\mathrm{rSO}_{2}$ values, as they were not measured for clinical purposes.

\section{Case 1}

A boy diagnosed prenatally with pulmonary atresia with an intact ventricular septum was born at our hospital at a gestational age of 37.3 weeks. After birth, the patient was admitted to the neonatal intensive care unit (NICU) with continuous positive airway pressure (CPAP) at seven $\mathrm{cmH}_{2} \mathrm{O}$ with a maximum of $40 \% \mathrm{O}_{2}$ and infusion with prostaglandin $E_{1}(0.025 \mathrm{ug} / \mathrm{kg} / \mathrm{min})$ to maintain pulmonary circulation. Prenatal diagnosis and ductal patency were confirmed by the pediatric cardiologist. The patient appeared to be hemodynamically stable with transcutaneous oxygen saturations $\left(\mathrm{SpO}_{2}\right)$ between $70 \%$ and $90 \%$ and mean arterial blood pressures between 46 and $73 \mathrm{mmHg}$. As the patient was clinically stable, further hemodynamic parameters were not available for this case.

Four hours after birth the boy developed three apneas. The third apnea was followed by loss of cardiac output. Cardiopulmonary resuscitation was initiated immediately according to protocol. Cardiac output and heart rate, however, remained insufficient and the boy died $6 \mathrm{~h}$ after birth.

Autopsy confirmed the diagnosis of a pulmonary atresia with a hypoplastic right ventricle and an intact ventricular septum. Furthermore, autopsy revealed a single coronary ostium, multiple ventricular-coronary fistulas and a right ventricle dependent coronary blood flow with bridging of a branch of the right coronary artery. There were signs of recent myocardial ischemia, such as loss of cardiomyocytes. In addition, there was a left-sided open ductus arteriosus between the brachiocephalic trunk and the pulmonary artery. Based on autopsy findings, the most likely cause of death was considered to be massive myocardial ischemia which is not uncommon for this type of anatomy and physiology. Other causes such as a primary intraventricular hemorrhage or infarction cannot be ruled out completely since there was no permission for cerebral autopsy.

\section{Near-infrared spectroscopy case 1}

Baseline cerebral and renal $\mathrm{rSO}_{2}$ were relatively low (around 40\%) and decreased rapidly approximately 40 min before cardiopulmonary resuscitation was necessary (Fig. 1). This rapid decrease in cerebral and renal $\mathrm{rSO}_{2-}$ was probably due to a sudden decrease in arterial oxygen saturation. All clinical parameters spontaneously recovered from this incident. Cerebral $\mathrm{rSO}_{2}$, however, started decreasing again from approximately $40 \%$ to $15 \% 25 \mathrm{~min}$ before cardiopulmonary resuscitation was necessary, while other hemodynamic parameters did not alarm the attending staff. Within $10 \mathrm{~min}$, cerebral $\mathrm{rSO}_{2}$ had already decreased $50 \%$ from its original baseline value $(40 \%)$ to approximately $20 \%$. We cannot fully explain why cerebral $\mathrm{rSO}_{2}$ decreased before renal $\mathrm{rSO}_{2}$ and $\mathrm{SpO}_{2}$.

\section{Case 2}

A girl diagnosed prenatally with double outlet right ventricle, transposed great arteries, a ventricular septal defect and a hypoplastic aortic arch was born prematurely at our hospital at a gestational age of 34.9 weeks.

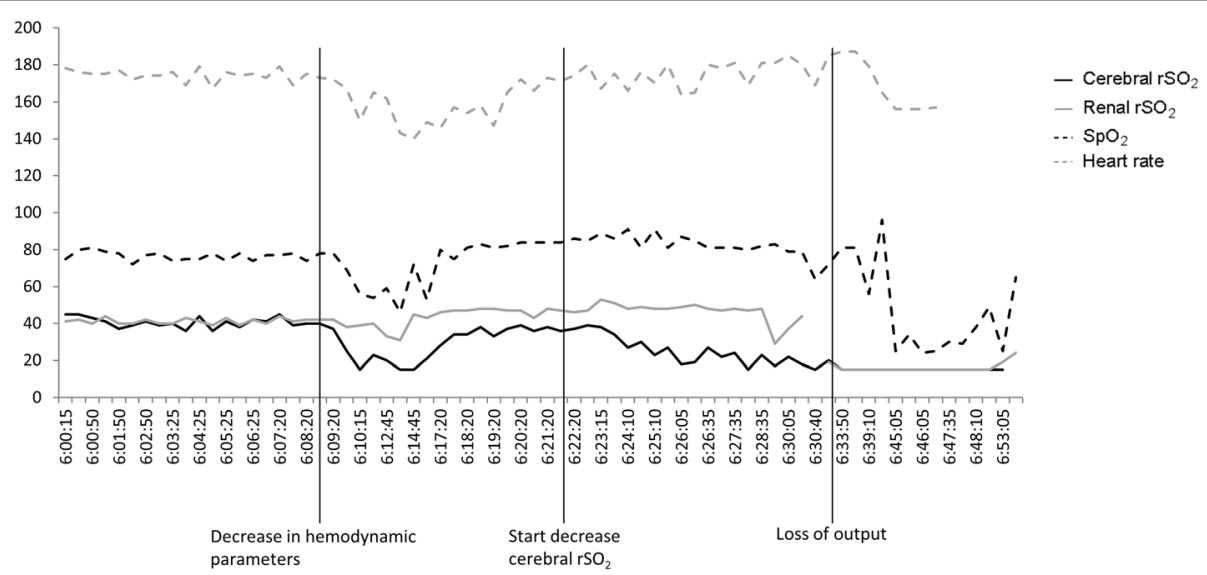

Fig. 1 The course of hemodynamic parameters and cerebral and renal oxygen saturation of the first case. $\mathrm{SpO}_{2}$, transcutaneous arterial oxygen saturation; $\mathrm{rSO}_{2}$, regional tissue oxygen saturation 
She was admitted to the NICU with CPAP $10 \mathrm{cmH}_{2} \mathrm{O}$ with a maximum of $40 \% \mathrm{O}_{2}$ due to respiratory distress/ delayed transition. Initially, she had a wide-open ductus arteriosus. Eighteen hours after birth her clinical condition deteriorated with signs of a duct-dependent systemic circulation. Therefore, prostaglandin $\mathrm{E}_{1}$ infusion was administered $(0.025 \mathrm{ug} / \mathrm{kg} / \mathrm{min})$ to maintain ductal patency. During the first days after birth there was a fragile balance between pulmonary and systemic blood flow.

At the sixth day after birth, she underwent bilateral pulmonary banding with the intention of controlling an ever increasing pulmonary blood flow. Peri-operatively, hypotension was treated successfully with multiple volume expansions and noradrenalin. Postoperatively, she was on Bi-level Positive Airway Pressure (BiPAP)-assist and prior to loss of output there were no clinical signs of primary respiratory failure (e.g. inadvertent extubation). Arterial $\mathrm{pH}$ was 7.34 , arterial saturation was $90 \%, \mathrm{pCO}_{2}$ was $4.8 \mathrm{kPa}$, hemoglobin was $8.0 \mathrm{mmol} / \mathrm{l}$ and lactate was $1.5 \mathrm{mmol} / \mathrm{l}$. At that time, arterial blood pressure was $70 / 30 \mathrm{mmHg}$ and she had normal diuresis. One hour later, she suddenly developed bradycardia followed by loss of cardiac output. Cardiopulmonary resuscitation was initiated immediately according to protocol. Infusion with prostaglandin $E_{1}$ was transferred from a peripheral venous site to a central line and was increased in dosage. An echocardiogram suggested an open ductus arteriosus, revealed a poor contractility and an inadequate cardiac output. After $40 \mathrm{~min}$ of cardiopulmonary resuscitation, the sternum was re-opened. The heart, however, was almost non-contractile and the girl died 7 days after birth.

Autopsy confirmed the diagnosis and concluded that the lumen of the ductus arteriosus was small with a diameter of less than three millimeter. Whether this was too small to maintain systemic circulation and whether prostaglandin $E_{1}$ infusion was inadequate at the time of collapse, remains unknown. Furthermore, autopsy revealed an immature lung parenchyma, atelectasis of part of the basal lobes and small inflammatory areas in both lungs. These pulmonary findings might also have contributed to the cardiopulmonary collapse.

\section{Near-infrared spectroscopy case 2}

We observed an increase in cerebral $\mathrm{rSO}_{2}$ and a decrease in renal $\mathrm{rSO}_{2} 1 \mathrm{~h}$ before loss of output (Fig. 2). Renal $\mathrm{rSO}_{2}$ returned to baseline, while cerebral $\mathrm{rSO}_{2}$ remained approximately $10 \%$ above baseline. This incident might have been caused by a closing ductus arteriosus due to insufficient Prostaglandin $E_{1}$ administration or an insufficient response to adequate Prostaglandin $E_{1}$ administration. Especially the rapidly decreasing renal $\mathrm{rSO}_{2}$ was indicative of a closing ductus arteriosus. Due to the coarctation of the aorta, renal blood flow was dependent on an open ductus arteriosus. The increase in cerebral $\mathrm{rSO}_{2}$ was less easy to explain, but could be caused by an increase in cerebral blood flow. Due to the closing ductus arteriosus, the descending aorta might have become narrower, leading to an increased arterial pressure above the coarctation and subsequently increased cerebral blood flow. Thirty minutes before cardiopulmonary resuscitation, cerebral $\mathrm{rSO}_{2}$ started decreasing from $55 \%$ to approximately $20 \%$ and renal $\mathrm{rSO}_{2}$ decreased from $40 \%$ to $15 \%$. Renal $\mathrm{rSO}_{2}$ decreased more rapidly compared with cerebral $\mathrm{rSO}_{2}$ and approximately $15 \mathrm{~min}$ before loss of output, renal $\mathrm{rSO}_{2}$ was less than $50 \%$ from its original baseline value. The more rapid decrease of renal $\mathrm{rSO}_{2}$ in comparison with cerebral $\mathrm{rSO}_{2}$ also supports the theory of insufficient systemic circulation due to a closing ductus arteriosus. Apart from a slowly increasing heart rate from $160 \mathrm{bpm}$ to $180 \mathrm{bpm}$, hemodynamic parameters such as

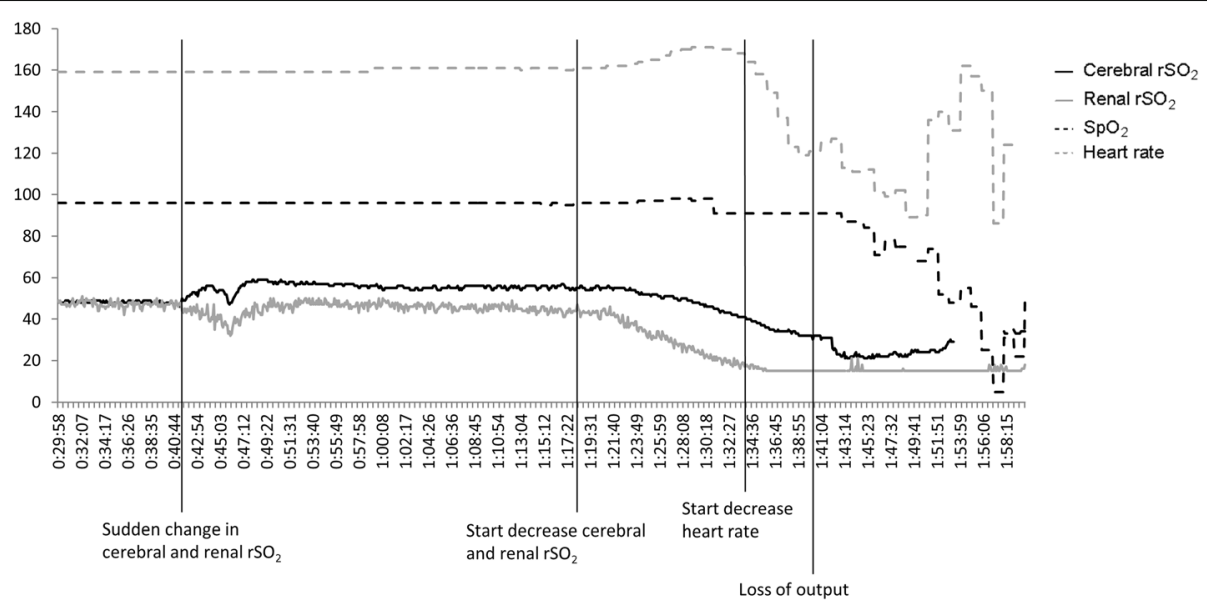

Fig. 2 The course of hemodynamic parameters and cerebral and renal oxygen saturation of the second case. $\mathrm{SpO}_{2}$, transcutaneous arterial oxygen saturation; $\mathrm{rSO}_{2}$, regional tissue oxygen saturation 
$\mathrm{SpO}_{2}$ and arterial blood pressure remained stable until several minutes before cardiopulmonary resuscitation was necessary (Fig. 2).

\section{Discussion}

These cases demonstrate that continuous monitoring of multisite near-infrared spectroscopy might be helpful in early identification of clinical deterioration in infants with congenital heart disease. In both cases, cerebral and/or renal $\mathrm{rSO}_{2}$ changed $30 \mathrm{~min}$ or more before loss of output while other hemodynamic parameters did not indicate that deterioration was imminent until a few minutes before cardiopulmonary resuscitation was necessary.

Cerebral $\mathrm{rSO}_{2}$ decreased 30-35\% from baseline before loss of output. McNeill et al. found that cerebral $\mathrm{rSO}_{2}$ values varied $15 \%$ or more from baseline $\mathrm{rSO}_{2}$ values during less than $1 \%$ of the day in preterm infants [15]. Furthermore, Bernal et al. demonstrated an average cerebral $\mathrm{rSO}_{2}$ of $77 \%$ with a standard deviation of $6.1 \%$ within patients during the first week after birth [16]. As a decrease of $30-35 \%$ exceeds this intra-individual variability, it seems more likely that the decrease in cerebral $\mathrm{rSO}_{2}$ observed in the two cases was a consequence of a deteriorating clinical condition and a subsequent reduction of cerebral perfusion, rather than the normal intraindividual variability of NIRS.

In the current cases we did not respond to changes in cerebral and renal $\mathrm{rSO}_{2}$, as they were measured in the context of a prospective observational cohort study and not for clinical purposes. In retrospect, these cases indicate that large changes in cerebral and/or renal $\mathrm{rSO}_{2}$ in infants with duct-dependent CHD should be considered a red flag and warrant a complete check-up of the infant, including physical examination, echocardiography and basic blood tests. The time-interval of 15 to 30 min might give some extra time to prevent clinical deterioration in infants with CHD. Potential therapeutic strategies depend on the reason of the change in cerebral and/or renal $\mathrm{rSO}_{2}$, but could include mechanical ventilation, pharmaceutical therapy (e.g. inotropes), volume expansion or perhaps emergency surgery. Furthermore, it might be useful to use predefined upper and lower limits of cerebral and renal oxygen saturation, a principle that was recently suggested in a large trial with preterm infants [17]. Due to the heterogeneity of the cardiac population, it is difficult to apply normal ranges of cerebral and renal $\mathrm{rSO}_{2}$. In this population it might be more useful to use limits below which histological and biochemical changes in tissue have been reported, i.e. below $44 \%$ [18].

\section{Conclusions}

In conclusion, in infants with duct-dependent congenital heart disease, a significant change in cerebral and/or renal oxygen saturation from baseline as measured by
NIRS may be an early indicator of a sudden, unexpected clinical deterioration, which eventually could lead to cardiac arrest and death. Increased awareness and thorough scrutiny of the patient are required when such changes in cerebral and/or renal oxygen saturation are observed.

\section{Abbreviations \\ BiPAP-assist: Bi-level Positive Airway Pressure - assist; CHD: Congenital heart disease; CPAP: Continuous positive airway pressure; NICU: Neonatal intensive care unit; NIRS: Near-infrared spectroscopy; $\mathrm{rSO}_{2}$ : Regional tissue oxygen saturation; $\mathrm{SpO}_{2}$ : Transcutaneous arterial oxygen saturation}

\section{Acknowledgements}

We would like to thank the nurses and staff of the neonatal intensive care unit and the pediatric intensive care unit for their help with the NIRS measurements.

\section{Funding}

This study was part of the research program of the Graduate School of Medical Sciences, Research Institutes BCN-BRAIN and GUIDE, University of Groningen. M.J. Mebius was financially supported by the Junior Scientific Master Class of the University of Groningen.

\section{Availability of data and materials}

The datasets during and/or analyzed during the current study are available from the corresponding author on reasonable request.

\section{Authors' contributions}

MJM made substantial contributions to the conception and design of the study, drafted the initial manuscript, revised the manuscript after feedback from co-authors, and approved the final manuscript as submitted. GJdMS was one of the pediatric cardiologists involved in the second case, made substantial contributions to the interpretation of data, critically reviewed the manuscript, and approved the final manuscript as submitted. DWW was the attending staff member in the second case, made substantial contributions to acquisition of data, critically reviewed the manuscript, and approved the final manuscript as submitted. BB was one of the pediatric cardiologists involved in the first case, made substantial contributions to acquisition of data, critically reviewed the manuscript, and approved the final manuscript as submitted. MCJK made substantial contributions to the interpretation of data, critically reviewed the manuscript, and approved the final manuscript as submitted. AFB made substantial contributions to the conception and design of the study, critically reviewed the manuscript, and approved the final manuscript as submitted. EMWK was the attending staff member in the first case, made substantial contributions to the conception and design of the study and the interpretation of data, critically reviewed the manuscript, and approved the final manuscript as submitted.

Authors' information

Not applicable

\section{Competing interests}

The authors declare that they have no competing interests.

\section{Consent for publication}

In both cases we received written informed consent from both parents to publish the information in this case report.

\section{Ethics approval and consent to participate}

The Medical Ethics Review Board University Medical Center Groningen ${ }^{1}$ approved the prospective observational cohort study and parental informed consent was obtained before inclusion in the study.

${ }^{1}$ University Medical Center Groningen, The Netherlands

Financial disclosure

None reported 


\section{Publisher's Note}

Springer Nature remains neutral with regard to jurisdictional claims in published maps and institutional affiliations.

\section{Author details}

'University Medical Center Groningen, Beatrix Children's Hospital, Division of Neonatology, University of Groningen, Hanzeplein 1, 9713 GZ Groningen, The Netherlands. 'University Medical Center Groningen, Beatrix Children's Hospital, Division of Pediatric Intensive Care, University of Groningen, Groningen, The Netherlands. ${ }^{3}$ University Medical Center Groningen, Center for Congenital Heart Diseases, Pediatric Cardiology, Beatrix Children's Hospital, University of Groningen, Groningen, The Netherlands. ${ }^{4}$ Critical Care, Anesthesiology, Peri-operative \& Emergency medicine (CAPE), the University of Groningen, Groningen, The Netherlands.

Received: 30 August 2016 Accepted: 11 March 2017

Published online: 16 March 2017

\section{References}

1. Ortmann L, Prodhan P, Gossett J, Schexnayder S, Berg R, Nadkarni V, et al. Outcomes after in-hospital cardiac arrest in children with cardiac disease: a report from Get With the Guidelines-Resuscitation. Circulation. 2011;124: 2329-37.

2. Berg MD, Nadkarni VM, Berg RA. Cardiopulmonary resuscitation in children. Curr Opin Crit Care. 2008;14:254-60.

3. Suominen P, Olkkola KT, Voipio V, Korpela R, Palo R, Rasanen J. Utstein style reporting of in-hospital paediatric cardiopulmonary resuscitation. Resuscitation. 2000;45:17-25.

4. Peddy SB, Hazinski MF, Laussen PC, Thiagarajan RR, Hoffman GM, Nadkarni $\checkmark$, et al. Cardiopulmonary resuscitation: special considerations for infants and children with cardiac disease. Cardiol Young. 2007;17 Suppl 2:116-26.

5. Wahr JA, Tremper KK, Samra S, Delpy DT. Near-infrared spectroscopy: theory and applications. J Cardiothorac Vasc Anesth. 1996:10:406-18.

6. Pellicer A, Bravo Mdel C. Near-infrared spectroscopy: a methodologyfocused review. Semin Fetal Neonatal Med. 2011;16:42-9.

7. Simons J, Sood ED, Derby CD, Pizarro C. Predictive value of near-infrared spectroscopy on neurodevelopmental outcome after surgery for congenital heart disease in infancy. J Thoracic Cardiovasc Surg. 2012;143:118-25.

8. Kussmann BD, Wypij D, Laussen PC, Soul JS, Bellinger DC, DiNardo JA, et al. Relationship of intraoperative cerebral oxygen saturation to neurodevelopmental outcome and brain magnetic resonance imaging at 1 year of age in infants undergoing biventricular repair. Circulation. 2010;122:245-54.

9. Chakravarti SB, Mittnacht AJ, Katz JC, Nguyen K, Joashi U, Srivastava S, et al. Multisite near-infrared spectroscopy predicts elevated blood lactate level in children after cardiac surgery. J Cardiothorac Vasc Anesth. 2009;23:663-7.

10. Zulueta JL, Vida VL, Perisinotto E, Pittarello D, Stellin G. Role of intraoperative regional oxygen saturation using near infrared spectroscopy in the prediction of low output syndrome after pediatric heart surgery. J Card Surg. 2013;28:446-52.

11. Toet MC, Flinterman A, Laar I, Vries JW, Bennink GB, Uiterwaal CS, et al. Cerebral oxygen saturation and electrical brain activity before, during, and up to 36 hours after arterial switch procedure in neonates without preexisting brain damage: its relationship to neurodevelopmental outcome. Exp Brain Res. 2005;165:343-50.

12. Uebing A, Furck AK, Hansen JH, Nufer E, Scheewe J, Dütschke P, et al. Perioperative cerebral and somatic oxygenation in neonates with hypoplastic left heart syndrome or transposition of the great arteries. J Thorac Cardiovasc Surg. 2011;142:523-30.

13. Kurth CD, Steven JL, Montenegro LM, Watzman HM, Gaynor JW, Spray TL, et al. Cerebral oxygen saturation before congenital heart surgery. Ann Thorac Surg. 2001;72:187-92.

14. Mebius MJ, Van der Laan ME, Verhagen EA, Roofthooft MTR, Bos AF, Kooi EMW. Cerebral oxygen saturation during the first $72 \mathrm{~h}$ after birth in infants diagnosed prenatally with congenital heart disease. Early Hum Dev. 2016; 103:199-203.

15. McNeill S, Gatenby JC, McElroy S, Engelhardt B. Normal cerebral, renal and abdominal regional oxygen saturations using near-infrared spectroscopy in preterm infants. J Perinatol. 2011;31:51-7.

16. Bernal NP, Hoffman GM, Ghanayem NS, Arca MJ. Cerebral and somatic nearinfrared spectroscopy in normal newborns. J Pediatr Surg. 2010;45:1306-10.
17. Pellicer A, Greisen G, Benders M, Claris O, Dempsey E, Fumagalli M, et al. The SafeBoosC phase II randomised clinical trial: a treatment guideline for targeted near-infrared-derived cerebral tissue oxygenation versus standard treatment in extremely preterm infants. Neonatology. 2013;104:171-8.

18. Kurth CD, Levy WJ, McCann J. Near-infrared spectroscopy cerebral oxygen saturation thresholds for hypoxia-ischemia in piglets. J Cereb Blood Flow Metab. 2002:22:335-41.

\section{Submit your next manuscript to BioMed Central and we will help you at every step:}

- We accept pre-submission inquiries

- Our selector tool helps you to find the most relevant journal

- We provide round the clock customer support

- Convenient online submission

- Thorough peer review

- Inclusion in PubMed and all major indexing services

- Maximum visibility for your research

Submit your manuscript at www.biomedcentral.com/submit 